\author{
Fariba KHALAFI, PhD Candidate \\ E-mail: fariba.khalafi20@yahoo.com \\ Department of Mathematics, Karaj Branch, Islamic Azad University \\ Karaj, Iran \\ Associate Professor Reza KAZEMI MATIN, PhD \\ E-mail: rkmatin@kiau.ac.ir (Corresponding author) \\ Department of Mathematics, Karaj Branch, Islamic Azad University \\ Karaj, Iran
}

\title{
POTENTIAL IMPROVEMENTS IN A NON-RADIAL INEFFICIENCY MEASUREMENT
}

Abstract. In this paper, a potential improvement approach to separate two issues of benchmark selection and efficiency measurement is studied. In this regard, a non-radial inefficiency in terms of Russell model is proposed. An interactive approach is considered to gain the appropriate operational benchmark as well. Illustrative numerical examples are solved to show various aspects of the proposed approach.

Keywords: Data envelopment analysis, potential improvement, non-radial inefficiency, Russell model.

JEL Classification: C61, C67

\section{Introduction}

Within a production economic framework the standard approach to performance evaluation involves the use of some index of technical efficiency in connection with an estimated production technology. For example, in Data Envelopment Analysis (DEA), Farrell's radial efficiency index is used with respect to a technology determined by the convex envelopment of the data points (Farrell, 1957 \& Charnes et al., 1978). In DEA the selection of a benchmark, for a given inefficient production plan, is implicitly performed by the programs which determine the efficiency score.

Bogetoft and Hougaard (1999) showed that there are several advantages in separating the issue of benchmark selection and the issue of inefficiency measurement. This separation highlights the economic assumption underlying the benchmark selection and enables a critical view on efficiency indexes since a suitable index ought to be based on a proper benchmark selection procedure.

To select a proper benchmark Bogetoft and Hougaard (1999) suggested looking for improvements in proportion to the potential improvements given by the input specific excesses. They showed, by axiomatic characterizations, that this selection procedure has several advantages compared to the implicit selection

DOI: $10.24818 / 18423264 / 55.3 .21 .10$ 
procedure used in DEA which is looking for improvements in proportion to past production.

Moreover, based on the improved selection procedure they suggest a well behaved inefficiency index which relates to Luenberger's excess function (Luenberger, 1992). This index is called the potential improvements inefficiency index. Then Asmild et al. (2003) re-examined the potential improvements inefficiency index and demonstrated how the Farrell index can be replaced with this new index in DEA-like models. That is, determination of the value of the potential improvements index for a finite group of similar production units can be done by solving a series of linear programming problems as in DEA. The suggested procedure called Multi-directional Efficiency Analysis (MEA) due to the fact that adjustments in production follow different directions in the product space depending on the location of the specific production plan at hand and the shape of its dominating set. Also Torben Holvad et al. (2004) demonstrated the advantages of MEA in the case of cost data with limited substitution possibilities. Baek and Lee (2009) proposed the use of the Least-Distance Measure in order to obtain the shortest projection from the evaluated Decision Making Unit (DMU) to the strongly efficient production frontier, thus allowing an inefficient DMU to find the easiest way to improve its efficiency. Wang et al. (2013a, 2013b) utilized the MEA approach instead of the traditional radial DEA to investigate Chinese regional energy and emissions efficiency. Also Asmild et al. (2009) with using MEA investigated how railway reforms affect the inefficiencies of specific cost drivers. Asmild and Matthews (2009) showed how difference in the efficiency patterns between different subgroups within a data set can be investigated using the MEA methodology. Thus Tomas Balezentis and Kristof De Witte (2015) analyses farming efficiency by the means of the partial frontiers and Multi Directional Efficiency Analysis (MEA) and Wang and et al.( 2013b) utilized MEA approach for evaluates the environmental efficiency of industrial sectors of Chinese major cities. Magdalena Kapelko, Alfons Oude Lansink (2016) extended MEA to account for dynamics of firm's production decisions.

The aim of this paper is to re-examine the potential improvements inefficiency index and Farrell index, then demonstrate how the normalized Russell inefficiency Index can be replaced with the potential improvements inefficiency index. The new inefficiency index is illustrated by analysis of data set on Cement Industry admitted in Iran's Stuck and then obtained results are compared with the Farrell inefficiency index.

The paper is organized as follows: Section 2 contains definition of the relevant concepts with respect to the potential improvements inefficiency index and illustrate graphically the ideas behind this approach and the difference from the Farrell index. Section 3 introduces a new Non-radial inefficiency index in terms of Russell Model in DEA. Section 4 describes the data set which will be used in the empirical analysis. Finally, Section 5 presents the results and makes comparisons with Farrell index. 
Potential Improvements in a Non-radial Inefficiency Measurement

\section{Potential Improvements Inefficiency Index}

This section proceeds to a review of Potential Improvements Inefficiency Index introduced by Bogetoft and Hagaard (1999) as well as recalls some fundamental concepts from DEA. Throughout the paper we focus on the inputs in order to simplify the exposition.

Let us show a given technology by $L(\mathbf{y}) \subset \mathbb{R}_{+}^{n}$, a set of input combinations, $\quad \mathbf{x} \in \mathbb{R}_{+}^{n}$, that can produce a fixed amount of output $\mathbf{y} \in \mathbb{R}_{+}^{m}$, where $L(\mathbf{y})$ is non-empty, closed, comprehensive and convex set. On the assumption $\mathbf{x} \in L(\mathbf{y})$, in the usual manner the dominating set of $\mathbf{x}$ and the strong efficient subset of $L(\mathbf{y})$ are defined in the forms $D(\mathbf{x})=\left\{\mathbf{x}^{\prime} \in L \mid \mathbf{x}^{\prime} \leq \mathbf{x}, \mathbf{x}^{\prime} \neq \mathbf{x}\right\}$ and Eff $L(\mathbf{y})=\left\{\mathbf{x}: \mathbf{x} \in L(\mathbf{y}), \mathbf{x}^{\prime} \leq \mathbf{x}, \mathbf{x}^{\prime} \neq \mathbf{x} \Rightarrow \mathbf{x}^{\prime} \notin L(\mathbf{y})\right\}, \quad$ in other words Eff $L(\mathbf{y})=\{\mathbf{x} \in L(\mathbf{y}) \mid D(\mathbf{x})=\varnothing\}$, respectively.

According to Bogetoft and Hagaard (1999), an ideal reference of $\mathbf{x}$ is introduced by $\mathbf{x}^{*}(\mathbf{x})=\left(x_{i}^{*}, i=1, \ldots, n\right)$ where $x_{i}^{*}=\min \left\{x_{i}^{\prime} \in \mathbb{R}_{+} \mid\left(x_{i}^{*}, \boldsymbol{x}_{-\boldsymbol{i}}\right) \in\right.$ $L(\boldsymbol{y})$, with $-i=\{1, \ldots, i-1, i+1, \ldots, n\}$.

The ideal reference point corresponds to the largest possible reduction in each input dimension taken separately. Obviously, $\mathbf{x}^{*}(\mathbf{x})$ depends on the location of $\mathbf{x}$ and if the location of $\mathbf{x}$ would be changed, then, it is concluded that the location of $\mathbf{x}^{*}$ has been changed. Then, in general it is not feasible. From now on, the term $\mathbf{x}^{*}$ will be used in the paper unless there may be ambiguity.

Based on Bogetoft and Hagaard (1999), the potential improvements selection $S^{P I}(\mathbf{x})=\mathbf{x}-e\left(\mathbf{x}, L, g^{P I}\right) g^{P I}$ is considered where the reference direction $g^{P I}$ is a vector proportional to $\mathbf{x}-\mathbf{x}^{*}$ (Figure1) and $e(\mathbf{x}, L, g)=\max \left\{\beta \in \mathrm{R}_{+} \mid \mathbf{x}-\beta g \in L, g \neq 0\right\}$, which is the excess function of Luenberger (1992). 


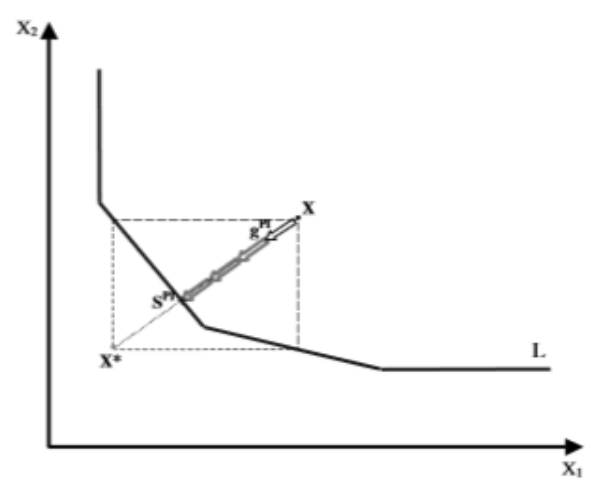

Figure 1. The potential improvements reference plan $S^{P I}$

Let $\mathbf{x} \in L(y)$. The normalized potential improvements inefficiency index, $E^{N P I}(\mathbf{x})$ for any $i=1, \ldots, n$ is defined in the following form:

$E^{N P I}(\mathbf{x})=\frac{x_{i}-S_{i}^{P I}}{x_{i}-x_{i}^{*}} \sum_{i=1}^{m} \frac{x_{i}-x_{i}^{*}}{x_{i}^{+}-x_{i}^{-}}$s.t $0<x_{i}^{-}<x_{i}^{+}<\infty, \forall i=1, \ldots, n$

It should be noted that $\frac{x_{i}-S_{i}^{P I}}{x_{i}-x_{i}^{*}}$ is constant for all $i$, because $g^{P I} \propto \mathbf{x}-\mathbf{x}^{*}$, where $\propto$ denotes proportionality. Therefore, $E^{N P I}(\mathbf{x})$ can be rewritten as,

$$
E^{N P I}(\mathbf{x})=\sum_{i=1}^{m} \frac{x_{i}-S_{i}^{P I}}{x_{i}^{+}-x_{i}^{-}}
$$

In other words, the normalized potential improvements index can be interpreted as a weighted sum of input excesses $x_{i}-S_{i}^{P I}$. On the other hand, $E^{N P I}(\mathbf{x})$ is continuous (jointly in $\mathbf{x}$ and $L(\mathbf{x})$ ), invariant with respect to affine transformations and strictly monotonous in inputs [5]. Obviously $E^{N P I}(\mathbf{x}) \geq 0$ and the input vector of that index related to the other inputs which are inefficient is decreasing. The normalized potential improvements index satisfies indication, i.e. $E^{N P I}(\mathbf{x})=0$ if and only if $\mathbf{x} \in E f f L(\mathbf{y})$ (see Bogetoft and Hagaard (1999)).

Now, by the use of Farrell efficiency measurement and based on the normalized potential improvements index, a normalized Farrell inefficiency index is defined as (3). It is well-known that the input-oriented Farrell efficiency measurement consists of $\theta^{F}=\min \{\theta \in \mathbb{R} \mid \theta \mathbf{x} \in L(\mathbf{y})\}, \quad \mathbf{x} \in L(\mathbf{y})$ and based on 
premises Farrell selection is $S^{F}=\theta^{F} . \mathbf{x}$; consequently, the normalized Farrell inefficiency index may now be defined as,

$$
E^{N F}(\mathbf{x})=\sum_{i=1}^{m} \frac{x_{i}-S_{i}^{F}}{x_{i}^{+}-x_{i}^{-}}=\left(1-\theta^{F}\right) \sum_{i=1}^{m} \frac{x_{i}}{x_{i}^{+}-x_{i}^{-}}
$$

Obviously, $E^{N F}(\mathbf{x}) \geq 0$ and its value increases as $\mathbf{x}$ gets more inefficient. However, $E^{N F}(\mathbf{x})$ does not satisfy indication, that is, $\mathbf{x} \in F(L)$ therefor $E^{N F}(\mathbf{x})=0 . E^{N F}(\mathbf{x})$ is unit invariant, but not invariant with respect to affine transformations. Also, this measure is strict monotonicity in inputs (See Bogetoft and Hagaard (1999)).

The Farrell efficiency measurement refers to efficiency, while the normalized potential improvements index measures signifies inefficiency. Fig 2 persuades us that the potential improvement is more useful than Farrell approach in order to measure inefficiency. Two production plans are equally Farrell-efficient (with score 0.5) but clearly the used excess inputs $\mathbf{x}-S^{P I}$ is larger for plan B than plan A. Comparing these indexes for the same data set may result in a dramatic change in the ranking of the production plans. For example, it can be expected that large production plans which may be relatively Farrell efficient will be relatively inefficient using $E^{N P I}$ due to a larger absolute sum of input excesses.

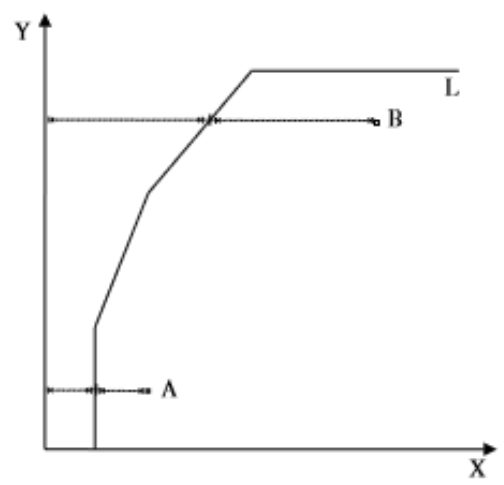

Figure 2. Absolute versus relative measures of inefficiency

Non-radial approaches in efficiency measurement of production units have attracted much attention for their ability to provide suitable efficiency measures, especially for discriminating strong and weak efficient production units. Some approaches like Russell, SBM, Additive Model, etc. are non-radial one.

In the rest of this paper, a new normalized Russell inefficiency index is proposed, based on potential improvements. Then, it is shown that the new model 
has stronger discriminating power than the normalized Farrell inefficiency index. It should be mentioned that non-radial Russell inefficiency index focuses on all inefficiencies. So, if there is a weak production plan, it will be introduced inefficient.

\section{The normalized Russell inefficiency Index}

In terms of the provided notations, we consider the input-oriented Russell efficiency measurement as $R M=\left\{\min \frac{1}{m} \sum_{i=1}^{m} \theta_{i} \mid\left(\theta_{1} x_{1}, \ldots, \theta_{m} x_{m}\right) \in L(\mathbf{y})\right\}$ where, $\forall i ; 0 \leq \theta_{i} \leq 1$ and $\left(x_{1}, \ldots, x_{m}\right) \in L(\mathbf{y})$. If there exists an index $i$ which $\theta_{i}=0, \quad i$-th input will omit from comparison.

At first, by the use of Russell selection $S^{R M}=\left(\theta_{1}^{*} x_{1}, \ldots, \theta_{m}^{*} x_{m}\right)$ a normalized Russell inefficiency index is defined in the following form:

$$
E^{N R M}(\mathbf{x})=\sum_{i=1}^{m} \frac{x_{i}-S_{i}^{R M}}{x_{i}^{+}-x_{i}^{-}}=\sum_{i=1}^{m}\left(1-\theta_{i}\right) \frac{x_{i}}{x_{i}^{+}-x_{i}^{-}}
$$

The idea of the Russell inefficiency index approach $E^{N R M}(\mathbf{x})$ allows estimating production possibilities to determine the improvement direction of $S^{R M}$ which some properties of this are given in the following proposition.

Proposition 1. The normalized Russell inefficiency index $E^{N R M}(\mathbf{x})$ satisfies:

1- $E^{N R M}(\mathbf{x}) \geq 0$

2- $E^{N R M}(\mathbf{x})$ Increasing if $\mathbf{x}$ gets more inefficient.

3- $E^{N R M}(\mathbf{x})=0$ if and only if $\mathbf{x} \in F(L)$.

4- $E^{N R M}(x)$ is unit invariant.

5- $E^{N R M}(x)$ is strongly monotonic in inputs.

6- $E^{N R M}\left(s^{R M}\right)=0$

\section{Proof:}

(1) For $i=1, \ldots, m: 0 \leq \theta_{i} \leq 1$, so $\left(1-\theta_{i}\right) \geq 0$ and therefore $\sum_{i=1}^{m} \frac{\left(1-\theta_{i}\right) x_{i}}{x_{i}^{+}-x_{i}^{-}} \geq 0$ So we have $E^{N R M}(\mathbf{x}) \geq 0$. 
Potential Improvements in a Non-radial Inefficiency Measurement

(2) If DMUA is dominated by DMUB, i.e. $\mathbf{x}_{A} \geq \mathbf{x}_{B}$, then $x_{i A}-S_{i A}^{R M} \geq x_{i B}-S_{i B}^{R M}$ and we have $\frac{x_{i A}-S_{i A}^{R M}}{x_{i}^{+}-x_{i}^{-}} \geq \frac{x_{i B}-S_{i B}^{R M}}{x_{i}^{+}-x_{i}^{-}}$. Therefore $E^{N R M}\left(\mathbf{x}_{A}\right) \geq E^{N R M}\left(\mathbf{x}_{B}\right)$, which implicates the index value $E^{N R M}(\mathbf{x})$ increases if $\mathbf{x}$ gets more inefficient.

(3) The normalized Russell inefficiency index satisfies indication, that is, $E^{N R M}(\mathbf{x})=0$ if and only if $\mathbf{x}$ is strong efficient, i.e. $\mathbf{x} \in F(L)$.

(4) RM is unit invariant, it means that for any $\alpha_{i}>0$ and $\beta_{r}>0$, (i $=$ $1, \ldots \mathrm{m}$, and $r=1, \ldots, \mathrm{s}$, ), if $\mathrm{x}_{\mathrm{ij}}$ change to $\alpha_{\mathrm{i}} \mathrm{x}_{\mathrm{ij}}$ and $\mathrm{y}_{\mathrm{rj}}$ change to $\beta_{\mathrm{r}} \mathrm{y}_{\mathrm{rj}}$ respectively, then RM will stay without change. So $E^{N R M}(x)$ will be remained the same.

(5) We showed if at least one of input increased by amount $\mathrm{k}$, for example

in constraint $\mathrm{t}, \quad$ if $x_{t o} \rightarrow x_{\text {to }}+k, k>0$, then, we have: $\left\{\begin{array}{c}\forall i, \text { if } \quad i=t \quad \theta_{t_{\text {new }}^{*}}^{*}<\theta_{t_{\text {old }}}^{*} \\ \text { if } \quad i \neq t \quad \theta_{i_{\text {new }}^{*}}^{*}=\theta_{i_{\text {old }}^{*}}\end{array}\right.$

As the result: $\left(1-\theta_{t_{\text {new }}}^{*}\right)>\left(1-\theta_{t_{\text {old }}}^{*}\right)$, so we may write:

$$
\left(1-\theta_{t_{\text {new }}}^{*}\right) \frac{x_{t o}+k}{x_{t}^{+}-x_{t}^{-}}>\left(1-\theta_{t_{\text {new }}}^{*}\right) \frac{x_{\text {to }}}{x_{t}^{+}-x_{t}^{-}}>\left(1-\theta_{t_{\text {old }}}^{*}\right) \frac{x_{\text {to }}}{x_{t}^{+}-x_{t}^{-}}
$$

Consequently, we get:

$$
\sum_{i=1, i \neq t}^{m}\left(1-\theta_{i_{\text {new }}}^{*}\right) \frac{x_{\text {io }}}{x_{i}^{+}-x_{i}^{-}}+\left(1-\theta_{t_{\text {new }}}^{*}\right) \frac{x_{\text {to }}+k}{x_{t}^{+}-x_{t}^{-}}>\sum_{i=1}^{m}\left(1-\theta_{i_{\text {old }}}^{*}\right) \frac{x_{\text {io }}}{x_{i}^{+}-x_{i}^{-}}
$$

Therefore, $E_{\text {new }}^{N R M}>E_{\text {old }}^{N R M}$. This completes the proof.

(6) The assertion, $E^{N R M}\left(s^{R M}\right)=0$, immediately concludes by the definition of $E^{N R M}(x)$.

The Russell inefficiency index has several attractive features compared to the Farrell inefficiency index. In particular, it distinguishes weakly efficient units from strongly efficient ones. Another difference between the normalized Russell inefficiency index and Farrell inefficiency index related to the selection of benchmarks. This is described in the following example. 
Fariba Khalafi, Reza Kazemi Matin

\section{Example 1:}

To illustrate the normalized Russell inefficiency index and to compare it with the normalized Farrell inefficiency index, an example of 8 production plans with two inputs and one output as Table 1 is given.

Table 1: Two inputs and one output case

\begin{tabular}{|c|c|c|c|c|c|c|c|c|}
\hline Plan & $\mathbf{A}$ & $\mathbf{B}$ & $\mathbf{C}$ & $\mathbf{D}$ & $\mathbf{E}$ & $\mathbf{F}$ & $\mathbf{G}$ & $\mathbf{H}$ \\
\hline $\mathbf{x}_{1}$ & 4 & 7 & 8 & 4 & 2 & 10 & 6 & 3 \\
\hline $\mathbf{x}_{2}$ & 3 & 3 & 1 & 2 & 4 & 1 & 4 & 7 \\
\hline $\mathbf{Y}$ & 1 & 1 & 1 & 1 & 1 & 1 & 1 & 1 \\
\hline
\end{tabular}

The normalized Russell inefficiency index $E^{N R M}(\mathbf{x})$ and the normalized Farrell inefficiency index $E^{N F}(\mathbf{x})$ for all production plans have been calculated. The results are reported in Table 2.

Table 2: Potential improvement for DMUs

\begin{tabular}{|c|c|c|c|c|c|c|c|c|}
\hline Plan & $\mathbf{A}$ & $\mathbf{B}$ & $\mathbf{C}$ & $\mathbf{D}$ & $\mathbf{E}$ & $\mathbf{F}$ & $\mathbf{G}$ & $\mathbf{H}$ \\
\hline$R M_{i}$ & 0.83 & 0.61 & 1 & 1 & 1 & 0.90 & 0.58 & 0.61 \\
\hline$E^{N R M}(\mathbf{x})$ & 0.16 & 0.54 & 0.00 & 0.00 & 0.00 & 0.25 & 0.58 & 0.62 \\
\hline$\theta^{F}$ & 0.85 & 0.63 & 1 & 1 & 1 & 1 & 0.60 & 0.66 \\
\hline$E^{N F}(\mathbf{x})$ & 0.14 & 0.50 & 0.00 & 0.00 & 0.00 & 0.00 & 0.50 & 0.51 \\
\hline
\end{tabular}

According to the previous discussions, first of all, efficiency score for each production plan is obtained. Then, $E^{N R M}(\mathbf{x})$ and $E^{N F}(\mathbf{x})$ are computed in the selected improvement direction. For example, the following linear programming is used to get Russell efficiency measure for Plan F: 
Potential Improvements in a Non-radial Inefficiency Measurement

$$
\begin{aligned}
R M= & \min \frac{1}{2}\left(\theta_{1}+\theta_{2}\right) \\
\text { s.t } \quad & \sum_{j=1}^{n} \lambda_{j} x_{1 j} \leq 10 \theta_{1} \\
& \sum_{j=1}^{n} \lambda_{j} x_{2 j} \leq 1 \theta_{2} \\
& \sum_{j=1}^{n} \lambda_{j} y_{j} \geq 1 \\
& \lambda_{j} \geq 0 \\
& \theta_{1} \leq 1, \theta_{2} \leq 1 \quad j=1, \ldots, 8
\end{aligned}
$$

At optimality, we get $R M_{F}^{*}=0.9, \theta_{1}^{*}=0.8, \theta_{2}^{*}=1$; consequently selected benchmark $\mathrm{F}$ is computed as $S_{F}^{R M}=\left(\theta_{1}^{*} x_{1}, \theta_{2}^{*} X_{2}\right)=(8,1)$. Russell inefficiency index given by (4) is also computed as follows:

$$
E^{N R M}=\frac{10-8}{10-2}+\frac{1-1}{7-1}=0.25
$$

Now, Farrell efficiency measure of plan $\mathrm{F}$ is evaluated by solving the following linear programming problem:

$$
\begin{array}{ll}
\theta^{F}\left(x_{F}\right)=\min \theta \\
\text { s.t } \quad 4 \lambda_{1}+7 \lambda_{2}+8 \lambda_{3}+4 \lambda_{4}+2 \lambda_{5}+10 \lambda_{6}+6 \lambda_{7}+3 \lambda_{8} \leq 10 \theta \\
& 3 \lambda_{1}+3 \lambda_{2}+\lambda_{3}+2 \lambda_{4}+4 \lambda_{5}+\lambda_{6}+4 \lambda_{7}+7 \lambda_{8} \leq 1 \theta \\
& \lambda_{1}+\lambda_{2}+\lambda_{3}+\lambda_{4}+\lambda_{5}+\lambda_{6}+\lambda_{7}+\lambda_{8} \geq 1 \\
& \lambda_{j} \geq 0 \quad, j=1, \ldots, 8
\end{array}
$$

Because the optimal solution is $\theta^{F^{*}}=1$, selected benchmark $\mathrm{F}$ is $S^{F}=\left(\theta^{*} x_{1}, \theta^{*} x_{2}\right)=(10,1)$. Therefore, Farrell inefficiency index given by (3) is computed as follows:

$$
E^{N F}\left(\mathbf{x}_{F}\right)=(1-1)\left(\frac{10}{10-2}+\frac{1}{7-1}\right)=0
$$

It should be noticed that $E^{N F}\left(\mathbf{x}_{F}\right)=0$ but $\mathbf{x}_{F} \notin F(L)$, and for all plans $E^{N F}(\mathbf{x}) \leq E^{N R M}(\mathbf{x})$ which is explained in the following proposition. 
Proposition 2: For $\mathbf{x} \in L(\mathbf{y}) ; E^{N F}(\mathbf{x}) \leq E^{N R M}(\mathbf{x})$.

Proof: According to optimal solution of Farrell model is a feasible solution of Russell models. So, if $\theta^{F}$ and $\mathrm{RM}=\left(\theta_{1}^{R}, \theta_{2}^{R}, \ldots, \theta_{m}^{R}\right)$ are optimal solutions of Farrell and Russell model respectively, then

$$
\theta_{1}^{R} \geq \theta^{F}, \theta_{2}^{R} \geq \theta^{F}, \ldots, \theta_{m}^{R} \geq \theta^{F},
$$

Also,

$$
\left(1-\theta_{1}^{R}\right) \leq\left(1-\theta^{F}\right), \quad\left(1-\theta_{2}^{R}\right) \leq\left(1-\theta^{F}\right), \ldots, \quad\left(1-\theta_{m}^{R}\right) \leq\left(1-\theta^{F}\right),
$$

Where, by setting in potential improvement:

$$
\sum_{i=1}^{m}\left(1-\theta_{i}^{R}\right) \frac{x_{i}}{x_{i}^{+}-x_{i}^{-}} \leq \sum_{i=1}^{m}\left(1-\theta^{F}\right) \frac{x_{i}}{x_{i}^{+}-x_{i}^{-}}
$$

Therefore, $E^{N F}(\mathbf{x}) \leq E^{N R M}(\mathbf{x})$ and proof is complete.

\subsection{An interactive approach}

In the majority of systems to get the best preferences of decision maker, it needs to use some restrictions which are given by decision maker. The reason of the use interactive approach is to receive preferences of decision maker. In the current paper there is an important question that is asked by decision maker: How could it be found the best operational point which its potential improvement is $E^{\prime}$. The reason of asking this question is the lack of the manager ability to receive $E^{N R M}$ because of some policy of his/her management. To the end, it is assumed that $E^{\prime}<E^{N R M}$. The proposed model to receive preferences decision maker is in the following form:

$$
\begin{array}{ll}
\min & =\sum_{i} \alpha_{i} \\
\text { s.t } & \sum_{i} \frac{\left(1-\alpha_{i}\right)}{x_{i}^{+}-x_{i}^{-}}=E^{\prime} \leq E^{N R M} \\
& 0<\theta_{i}^{*} \leq \alpha_{i} \leq 1 \\
& i=1, \ldots, m
\end{array}
$$

The aim of proposing model (5) is to obtain minimum of inputs rational decrease, allows to achieve the potential improvement $E^{\prime}$ suggested by DM. So, the 
operational point to achieve $E^{\prime}$ for $\mathrm{DMU}_{\mathrm{j}}$ is suggested as follows: $E^{\prime}\left(\alpha_{i}^{*} x_{i j}, y_{r j}\right) \quad j=1, \ldots, n$

Where $\alpha_{i}^{*}$ is the optimal value of (5). To illustrate, we consider $D M U_{A}$ in example 1. As it is shown in Table (2), $E^{N R M}=0.16$. Now, suppose we want to achieve $E^{\prime}=0.08$. The question is "how much decrease in inputs of this unit is need to achieve the new target vale for $E$ '?". One way to answer this question is to apply the model (5). Model (5) can be rewritten in the following form for $D M U_{A}$ :

$$
\begin{aligned}
& \min \alpha_{1}+\alpha_{2} \\
& \text { s.t } \frac{\left(1-\alpha_{1}\right)(4)}{10-2}+\frac{\left(1-\alpha_{2}\right)(3)}{10-2}=0.08 \leq 0.16
\end{aligned}
$$

The optimal solution of the problem is $\left(\alpha_{1}^{*}, \alpha_{2}^{*}\right)=(0,0.84)$, which shows that the second input should be decrease by 26 percent. Table (3) shows the original points and operational points of $D M U_{A}$.

Table 3: Operational point of $\mathrm{DMU}_{\mathrm{A}}$ with potential improvement $E^{\prime}=0.08$

\begin{tabular}{|c|c|c|}
\hline$D M U_{A}$ & Original point & Operational points \\
\hline $\mathbf{x}_{\mathbf{1}}$ & 4 & 4 \\
\hline $\mathbf{x}_{\mathbf{2}}$ & 3 & 2.52 \\
\hline $\mathbf{Y}$ & 1 & 1 \\
\hline
\end{tabular}

As the result shows, $D M U_{A}$ to get $E^{\prime}=0.08$ needs to lose some its second input from 3 to 2.52 , while the first input does not need to lose.

\section{Case study}

This section proceeds to an illustrative real example to show our approach. This example uses data from Cement Industry of Iran which consists in 19 companies in 2017.

Iran produces 1.4 percent of the world's cement. During the year 2016, Iran's cement production amounted to about 56.4 million tons, which is the fifth largest producer in the world, with China, India, the United States and Turkey following this production volume. According to the latest news, Iran's production capacity is over 80 million tons of clinker per year, and with this capacity, in fact, 
Fariba Khalafi, Reza Kazemi Matin

Iran has the third largest production capacity in the world with more than 70 production units. Considering the importance of this industry in Iran, it is essential to address the issue of efficiency and performance evaluation of the subsectors of this industry. After an interview with experts in this area, important factors of performance evaluation were identified, including 6 factors. These factors show inputs and outputs as follows:

- Inputs: Get Financial Facility $\left(I_{1}\right)$, Financial expenses $\left(I_{2}\right)$, Total financial $\operatorname{debt}\left(I_{3}\right)$.

- Outputs: Operating Profit $\left(O_{1}\right)$, capital $\left(O_{2}\right)$, Dividends payable $\left(O_{3}\right)$.

The information of companies' data is given in Table (4). We refer http://codel.ir to see data.

Table 4: Inputs and outputs data companies of Cement Industry

\begin{tabular}{|c|c|c|c|c|c|c|}
\hline Companies & $\boldsymbol{I}_{\mathbf{1}}$ & $\boldsymbol{I}_{\mathbf{2}}$ & $\boldsymbol{I}_{\mathbf{3}}$ & $\boldsymbol{O}_{\mathbf{1}}$ & $\boldsymbol{O}_{\mathbf{2}}$ & $\boldsymbol{O}_{\mathbf{3}}$ \\
\hline $\mathbf{1}$ & 218000 & 48493 & 802385 & 143616 & 300000 & 307787 \\
\hline $\mathbf{2}$ & 125000 & 24040 & 1116312 & 195492 & 400000 & 714423 \\
\hline $\mathbf{3}$ & 216210 & 41622 & 768061 & 102198 & 200000 & 8937 \\
\hline $\mathbf{4}$ & 0 & 79531 & 1226822 & 138852 & 392000 & 644391 \\
\hline $\mathbf{5}$ & 136000 & 14413 & 607722 & 141110 & 55000 & 245044 \\
\hline $\mathbf{6}$ & 3512143 & 272821 & 3857251 & 104452 & 1750000 & 695260 \\
\hline $\mathbf{7}$ & 30000 & 10665 & 577570 & 162267 & 125000 & 157490 \\
\hline $\mathbf{8}$ & 70000 & 16400 & 684889 & 93996 & 230000 & 237126 \\
\hline $\mathbf{9}$ & 85000 & 22371 & 333177 & 59867 & 900000 & 15322 \\
\hline $\mathbf{1 0}$ & 18000 & 74799 & 1219417 & -93121 & 641697 & 178363 \\
\hline $\mathbf{1 1}$ & 20000 & 2504 & 197045 & 16367 & 50000 & 87835 \\
\hline $\mathbf{1 2}$ & 1704750 & 172922 & 1590272 & 176538 & 450000 & 514930 \\
\hline $\mathbf{1 3}$ & 9639 & 9687 & 838185 & 96021 & 826978 & 368115 \\
\hline $\mathbf{1 4}$ & 130000 & 118099 & 1384964 & 96600 & 550000 & 608241 \\
\hline $\mathbf{1 5}$ & 260100 & 13614 & 592624 & 64229 & 233000 & 248621 \\
\hline $\mathbf{1 6}$ & 325000 & 44137 & 745253 & 84296 & 53222 & 276563 \\
\hline $\mathbf{1 7}$ & 0 & 23 & 864008 & -94180 & 208833 & 211974 \\
\hline $\mathbf{1 8}$ & 0 & 2889 & 757992 & 214141 & 660960 & 501766 \\
\hline $\mathbf{1 9}$ & 714593 & 83954 & 2166275 & 236252 & 273996 & 899765 \\
\hline & & & & & & \\
\hline
\end{tabular}


Potential Improvements in a Non-radial Inefficiency Measurement

To compute companies' potential improvement index, models (3) and (4) are used. The results are given in Table (5).

Table 5: Companies potential improvement

\begin{tabular}{|c|c|c|}
\hline Companies & $E^{N F}(\mathbf{x})$ & $E^{N R M}(\mathbf{x})$ \\
\hline $\mathbf{1}$ & 0.16 & 0.31 \\
\hline $\mathbf{3}$ & 0.01 & 0.11 \\
\hline $\mathbf{4}$ & 0.22 & 0.32 \\
\hline $\mathbf{5}$ & 0.12 & 0.34 \\
\hline $\mathbf{6}$ & 0.04 & 0.11 \\
\hline $\mathbf{7}$ & 1.98 & 2.57 \\
\hline $\mathbf{8}$ & 0.001 & 0.04 \\
\hline $\mathbf{9}$ & 0.12 & 0.16 \\
\hline $\mathbf{1 0}$ & 0 & 0 \\
\hline $\mathbf{1 1}$ & 0.29 & 0.40 \\
\hline $\mathbf{1 2}$ & 0.02 & 0.03 \\
\hline $\mathbf{1 3}$ & 0.79 & 1.33 \\
\hline $\mathbf{1 4}$ & 0 & 0 \\
\hline $\mathbf{1 5}$ & 0.28 & 0.58 \\
\hline $\mathbf{1 6}$ & 0.10 & 0.17 \\
\hline $\mathbf{1 7}$ & 0.20 & 0.33 \\
\hline $\mathbf{1 8}$ & 0 & 0 \\
\hline $\mathbf{1 9}$ & 0 & 0 \\
\hline & 0.41 & 0.71 \\
\hline
\end{tabular}

The second column of Table (5) shows potential improvement in Farrell model and the third column shows potential improvement in the new proposed model. As is seen, the new proposed potential improvements are greater than the computed results of Farrell model; this is proved as Proposition 2. Another remarkable point is that efficient companies in both ways have zero potential improvement index. In fact, these DMUs are strong efficient.

It should be noted that the arithmetic mean of the results obtained from the Farrell Potential Improvement is 0.2495 , while the arithmetic mean of the results of the proposed model based on Russell's non-radial model is of 0.3952 . Which show 
Fariba Khalafi, Reza Kazemi Matin

difference between two models' results. On the other hand, the potential improvement in proposed model for companies 2, 4, 5, 7, and 14 is more than Farrell one, more than two times. As already mentioned this is due to the fact that the proposed model is non-radial and considers all sources of inefficiency for companies.

Now suppose that, based on DM preferences, we would halve inefficient companies' potential improvement. To do this, it needs to determine the decreasing capacity of inputs to improve potential improvements. By applying model (4) and getting $\alpha_{i}^{*}$ and then using model (5), optimal inputs of benchmarks are obtained.

Table (6) shows nonzero inefficient companies' potential improvement for several improvements steps. At first, the improvement is 25 percent. Next, the improvement increases to 50 percent and finally it increases to 75 percent. According to these improvements scenarios, projection points (operational points) are given in Table (6).

Table 6: Benchmarks inputs as their potential improvements be halves

\begin{tabular}{|c|c|c|c|c|c|c|c|c|c|}
\hline & \multicolumn{3}{|c|}{$\% 25$} & \multicolumn{3}{|c|}{$\% 50$} & \multicolumn{3}{|c|}{$\% 75$} \\
\hline $\begin{array}{c}\text { Companie } \\
\mathbf{s}\end{array}$ & $I_{1}$ & $I_{2}$ & $I_{3}$ & $I_{1}$ & $I_{2}$ & $I_{3}$ & $I_{1}$ & $I_{2}$ & $I_{3}$ \\
\hline 1 & 21800 & 4849.3 & 741438 & 21800 & $\begin{array}{c}21448.7 \\
1\end{array}$ & 802385 & 21800 & $\begin{array}{c}42590.5 \\
6\end{array}$ & 802385 \\
\hline 2 & 12500 & $\begin{array}{c}10272.3 \\
6\end{array}$ & 1116312 & 12500 & 17774.3 & 1116312 & $\begin{array}{c}28416.0 \\
7\end{array}$ & 24040 & 1116312 \\
\hline 3 & 21621 & 4162.2 & $\begin{array}{c}595012 . \\
4\end{array}$ & 21621 & $\begin{array}{c}13088.5 \\
9\end{array}$ & 768061 & 21621 & $\begin{array}{c}34912.4 \\
3\end{array}$ & 768061 \\
\hline 4 & 0 & 9967.51 & 1226822 & 0 & $\begin{array}{c}33155.3 \\
4\end{array}$ & 1226822 & 0 & $\begin{array}{c}56343.1 \\
7\end{array}$ & 1226822 \\
\hline 5 & 13600 & 1903.73 & $\begin{array}{c}601155 . \\
4\end{array}$ & 13600 & 8916.26 & 607722 & $\begin{array}{c}39416.0 \\
7\end{array}$ & 14413 & 607722 \\
\hline 6 & $\begin{array}{c}351214 . \\
3\end{array}$ & $\begin{array}{c}27282.1 \\
0\end{array}$ & 3390852 & $\begin{array}{c}351214 . \\
3\end{array}$ & $\begin{array}{c}167793 . \\
8\end{array}$ & 3857251 & 1255591 & 272821 & 3857251 \\
\hline 7 & 3000 & 4578.22 & 577570 & 3000 & 7306.20 & 577570 & 3000 & $\begin{array}{c}10034.1 \\
9\end{array}$ & 577570 \\
\hline 8 & 7000 & 1640 & $\begin{array}{c}509359 . \\
2\end{array}$ & 7000 & 1640 & $\begin{array}{c}655767 . \\
4\end{array}$ & 7000 & $\begin{array}{c}10381.4 \\
7\end{array}$ & 684889 \\
\hline 10 & 1800 & 7479.9 & 1041477 & 1800 & 21497.7 & 1219417 & 1800 & 48777.5 & 1219417 \\
\hline 11 & 2000 & 443.15 & $\begin{array}{c}161100 . \\
1\end{array}$ & 2000 & 380.86 & $\begin{array}{c}189387 . \\
4\end{array}$ & 2000 & 1856.12 & 197045 \\
\hline 12 & 170475 & $\begin{array}{c}80525.7 \\
8\end{array}$ & $\begin{array}{c}777878 . \\
2\end{array}$ & 170475 & $\begin{array}{c}171231 . \\
1\end{array}$ & $\begin{array}{c}777878 . \\
2\end{array}$ & 1316493 & 172922 & $\begin{array}{c}777878 . \\
2\end{array}$ \\
\hline 14 & 13000 & 43260.3 & $\begin{array}{c}918838 . \\
3\end{array}$ & 13000 & $\begin{array}{c}82816.0 \\
1\end{array}$ & $\begin{array}{c}918838 . \\
3\end{array}$ & 13000 & 118099 & $\begin{array}{c}976166 . \\
6\end{array}$ \\
\hline 15 & 26010 & 1361.4 & $\begin{array}{c}534302 . \\
9\end{array}$ & $\begin{array}{c}119314 . \\
2\end{array}$ & 1361.4 & 592624 & 260100 & 2020.08 & 592624 \\
\hline 16 & 32500 & 4413.7 & $\begin{array}{c}677161 . \\
5\end{array}$ & 32500 & $\begin{array}{c}21844.6 \\
3\end{array}$ & 745253 & 35248.2 & 44137 & 74523 \\
\hline 19 & 71459.3 & 8395.4 & 1901252 & 71459.3 & $\begin{array}{c}37064.7 \\
1\end{array}$ & 2166275 & $\begin{array}{c}91187.6 \\
2\end{array}$ & 83954 & 2166275 \\
\hline
\end{tabular}

168 
Potential Improvements in a Non-radial Inefficiency Measurement

Table (6) presents three improvements scenarios for companies. For example, company 1 has a potential improvement of 0.31 with main inputs $(218000,48493,802385)$. At the first improvement, if the given potential is 0.23 , the inputs must be $(218000,4849.3,741438)$. This means that without changing the first input and reducing the second and third inputs to 90 and 7.5 percent, respectively, the potential improvement achieves 0.23 . Next, to achieve the potential improvement 0.15 , the inputs must be $(218000,21448.71,802385)$, in which case it is not necessary to change the first and third inputs. It just needs the second input reduces to 5.5 percent. Finally, to achieve potential improvement 0.07 , inputs must be $(218000,42590.56,802385)$. That is, it just needs to reduce the second input to 12 percent.

It is important to note that to improve efficiency it is not necessitate that the operational point in all of the main components is smaller than the original input. On the other hand, some inputs may need to be consumed more, which is confirmed by Company 1 . Therefore, managers of inefficient companies in the cement industry can, in several improvements, improve their inputs to a better position than the current position.

\section{Conclusions}

This paper reexamines the potential improvements inefficiency index and demonstrates how the index values can be calculated by a non-radial measure. This method is called the Russell inefficiency index. To illustrate the method, the paper uses data of the Cement industry of Iran's stuck. Furthermore, the illustrative example is used to compare the Russell potential inefficiency index with the Farrell potential inefficiency index. Since the Russell inefficiency scores are absolute, large inefficient branches tend to get large Russell inefficiency scores. This aspect has a crucial impact when the Russell inefficiency index scores are compared to the relative scores of the Farrell inefficiency index. Thus, despite a large correlation on both scores and rankings especially small and large branches have considerable deviations. Comparing the Russell inefficiency index scores with the Farrell inefficiency index scores reveal that the scores generally are larger. Furthermore, the differences between scores are independent of all characteristics of the data set and thus indicate a fundamental difference between the methods. Also, based on the DM's opinion a new optimization model to get a suggested potential improvement is proposed. The provided application shows the applicability of the newly proposed method.

\section{REFERENCES}

[1] Asmild, M., Holvad, T., Hougaard, J.L., Kronborg. D. (2009), Railway Reforms: Do they Influence Operating Efficiency? Transportation, 36:617-638; [2] Asmild, M., Hougaard, J.L., Kronborg. D., Kvist. H.K. (2003), Measuring Inefficiency via Potential Improvements. J Product Anal, 19:59-76; 
[3] Asmild, M., Matthews, K. (2012), Multi-directional Efficiency Analysis of Efficiency Patterns in Chinese Banks 1997-2008. Eur J Oper Res, 219:434-441; [4] Asmild, M., Pastor, J.T. (2010), Slack Free MEA and RDM with Comprehensive Efficiency Measures. Omega, 38:475-483:

[5] Bogetoft, P., Hougaard, J. L. (1999), Efficiency Evaluations Based on Potential (Non-Proportional) Improvements. Journal of Productivity Analysis, 12: 231-245;

[6] Charnes, A.,Cooper, W. W., Rhodes, E.(1978),Measuring the Efficiency of Decision Making Units. European Journal of Operational Research, 2: 429-444;

[7] Baek, C., Lee, J. (2009), The Relevance of DEA Benchmarking Information and the Least-Distance Measure. Mathematical and Computer Modelling, 265275;

[8] Farrell, M. J. (1957), The Measurement of Productive Efficiency. Journal of the Royal Statistical Society, Series A, III, 253-290;

[9] Holvad, T., Hougaard, J. L., Kronborg, D., Kvist, H. K. (2004), Measuring Inefficiency in the Norwegian Bus Industry Using Multi-directional Efficiency Analysis. Transportation, 31:349-369;

[10] Luenberger, D. G. (1992), Benefit Functions and Duality. Journal of Mathematical Economics, 21: 461-481;

[11] Kapelko, M., Lansink, A. O. (2016), Dynamic Multi-directional Inefficiency Analysis of European Dairy Manufacturing Firms. European Journal of Operational Research, Volume 257, 338-344;

[12] Shaneth., A. Estrad., H. Song, S., Young, A. K., Hyeo Namn, S. U., Shin, C., K. (2009), A Method of Stepwise Benchmarking for Inefficient DMUs Based on the Proximity Based Target Selection. Journal homepage, 11595-11604;

[13] Balezentisa, T., Witte, K.D. (2015), One and Multi-directional Conditional Efficiency Measurement Efficiency in Lithuanian Family Farms. European Journal of Operational Research, 612-622;

[14] Torben, H., Jens, H., Dorte, K., Hans, K.(2004), Measuring Inefficiency in the Norwegian Bus Industry Using Multi-directional Efficiency Analysis;

Transportation, Springer, vol. 31(3), pages 349-369, August;

[15] Wang, K., Wei, Y. M., Zhang, X. (2013a), Energy and Emissions Efficiency Patterns of Chinese Regions: A Multi- directional Efficiency Analysis. Appl Energy, 104:105-116;

[16] Wang, K., Yu, S., Zhang, W. (2013b), China's Regional Energy and Environmental Efficiency: A DEA Window Analysis Based Dynamic Evaluation. Math Comput Model, 58:1117-1127;

[17] Wang, K., Yu, S.W., Li, M.J., Wei, Y.M. (2015), Multi-directional Efficiency Analysis-Based Regional Industrial Environmental Performance Evaluation of China. Nat Hazards. 